\title{
Chapter 23: Learning and Work: Professional Learning Analytics
}

\author{
Allison Littlejohn \\ Institute of Educational Technology, Open University, United Kingdom \\ DOI: 10.18608/hla17.023
}

\begin{abstract}
Learning for work takes various forms, from formal training to informal learning through work activities. In many work settings, professionals collaborate via networked environments leaving various forms of digital traces and "clickstream" data. These data can be exploited through learning analytics (LA) to make both formal and informal learning processes traceable and visible to support professionals with their learning. This chapter examines the state-of-the-art in professional learning analytics (PLA) by considering how professionals learn, putting forward a vision for PLA, and analyzing examples of analytics in action in professional settings. LA can address affective and motivational learning issues as well as technical and practical expertise; it can intelligently align individual learning activities with organizational learning goals. PLA is set to form a foundation for future learning and work.
\end{abstract}

Keywords: Professional learning, formal training, informal learning

Professional learning is a critical component of ongoing improvement, innovation, and adoption of new practices for work (Boud \& Garrick, 1999; Fuller et al., 2003; Engeström, 2008). In an uncertain business environment, organizations must be able to learn continuously in order to deal with continual change (IBM, 2008). Learning for work takes different forms, ranging from formal training to discussions with colleagues to informal learning through work activities (Eraut, 2004; Fuller et al., 2003). These actions can be conceived of as different learning contexts producing a variety of data that can be used to improve professional learning and development (Billett, 2004; Littlejohn, Milligan, \& Margaryan, 2012). In contemporary workplaces, professionals tend to collaborate via networked environments, using digital resources, leaving various forms of digital traces and "clickstream" data. Analysis of these different types of data potentially provides a powerful means of improving operational effectiveness by enhancing and supporting the various ways professionals learn and adapt.

For some years now, employers have been aware of the potential of learning analytics to support and enhance professional learning (Buckingham Shum \& Ferguson, 2012). Learning analytics (LA) is an emerging methodological and multidisciplinary research area aimed at "the measurement, collection, analysis and reporting of data about learners and their contexts, for the purposes of understanding and optimizing learning and the environments in which it occurs" (Siemens \& Long, 2011, p. 34).

The vision for LA in education was of multifaceted systems that could leverage data and adaptive models of pedagogy to support learning (Baker, 2016; Berendt, Vuorikari, Littlejohn, \& Margaryan, 2014). These systems would mine the massive amounts of data generated as a by-product of digital learning activity to support learners in achieving their goals (Ferguson, 2012). However, the systems developed for use in university education have been much simpler, focusing on economic concerns associated with higher education cost and impact in terms of learner outcomes (Nistor, Derntl, \& Klamma, 2015; HEC Report, 2016). Many LA systems are based on predictive models that analyze individual learner profiles to forecast whether a learner is "at risk of dropping out" (Siemens \& Long, 2011, p. 36; Wolff, Zdrahal, Nikolov, \& Pantucek, 2013; Berendt et al. 2014; Nistor et al., 2015). These data are then presented to learners or teachers using a variety of dashboards. Current research is focusing on the actions taken to follow up on this feedback (Rienties et al., 2016). 
In educational settings, learning is focused on course objectives. However, in organizational settings learning processes have to be aligned with organizational and project goals (Kimmerle, Cress, \& Held, 2010). Learning tends to be planned around annual performance review processes, usually overseen by a Human Resource department. This type of system works well in organizations where large groups have standard work tasks and plan similar development activities.

In many organizations, however, job roles are becoming specialized, requiring unique and personalized development planning. In these circumstances, the "top down" planning models, where goals and priorities are planned and sequenced from the outset, may not be effective. Some organizations are shifting from top-down and individualized development planning using enterprise systems to adaptive and collaborative activity planning based around grassroots use of technologies, shifting towards "smart" or "agile" development planning where project teams have discretion to change the direction of the project over time (Clow, 2013). This means that development goals cannot be planned at the beginning of each development cycle; new and emerging priorities arise as each project unfolds. Agile planning systems require adaptive, just-in-time learning where people acquire the knowledge they need for new work tasks as the tasks emerge. However, this means that professionals have to be able to plan and self-regulate their own learning and development, changing their learning priorities as their work tasks evolve (Littlejohn et al., 2012).

\section{HOW PROFESSIONALS LEARN}

Learning in educational settings tends to focus around individual learner outcomes and explicit pedagogical models. Professional learning, however, is driven by the demands of work tasks and is interwoven with work processes (Eraut, 2000). By "professional learning," I mean the activities professionals engage in to stimulate their thinking and professional knowledge, to improve work performance and to ensure that practice is informed and up-to-date (Littlejohn \& Margaryan, 2013, p. 2).

Professionals themselves tend to think of learning in terms of training or formal learning (Eraut, 2000). Yet, there is a growing body of evidence that professional learning is more effective when integrated with work tasks (see, for example, Collin, 2008; Tynjälä, 2008; Fuller \& Unwin, 2004; Eraut, 2004). This type of learning is difficult to distinguish from everyday work tasks, so professionals may not recognize instances of learning (Argyris \& Schön, 1974; Engeström, 1999).

Eraut's (2004) work in particular foregrounds the importance of on-the-job learning, broadly describing professional learning as "intentional" and planned or "unintentional" and opportune. According to Tynjälä (2008) intentional learning may be pre-planned and structured as formal learning, for example degree programmes, classroom training, practical workshops, coaching or mentoring; other forms are less easy to recognize, for example asking a colleague for help or watching an expert perform a task. Learning can result as an "unintended" consequence of work activity (Eraut, 2000). A manager in finance organization might improve his inter-cultural competencies over time as new colleagues from branches around the world join his team (Littlejohn \& Hood, 2016). Professionals may be unaware of this sort of experiential learning until they reflected on how their practice has evolved over time. These different forms of professional learning are illustrated in the typology in Figure 23.1

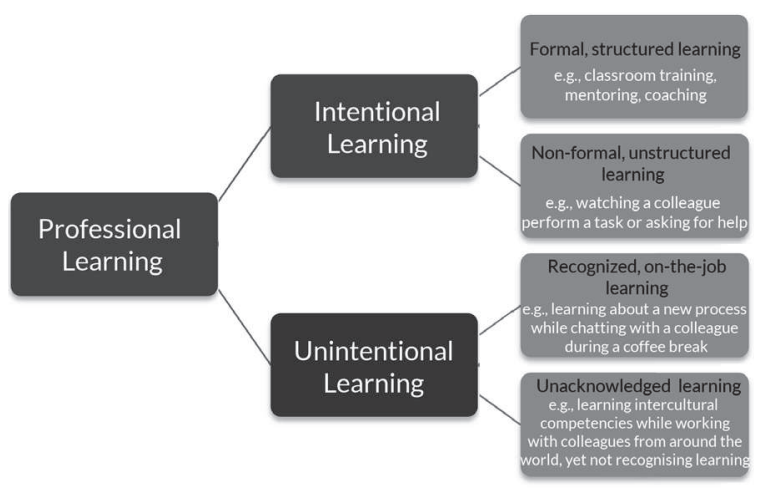

Figure 23.1. Typology of professional learning, informed by Eraut $(2000,2004)$.

The different approaches to learning illustrated in Figure 23.1 facilitate development of different types of knowledge (Tynjälä \& Gijbels, 2012; Littlejohn \& Hood, 2016). Education and training tend to focus on learning theoretical and practical knowledge, while coaching and mentoring allow opportunities to learn sociocultural and self-regulative knowledge, for example. All these knowledge types are critical for the adoption of new practices for work. Change in practice requires the construction of conceptual and practical knowledge as well as the development of sociocultural and self-regulative knowledge (Eraut, 2007). Construction of multiple types of knowledge is most readily achieved through a combination of formal (structured, pre-planned) learning activities with informal (unstructured, on-the-job) learning (Harteis \& Billett, 2008). As such, workplace learning operates as a reciprocal process (Billett, 2004) shaped by the affordances of a specific workplace, together with an individual's ability and motivation to engage with what is afforded (Billett, 2004; Fuller \& Unwin, 2004). 
Learning processes for work are more dynamic than in educational settings; Informal learning activities are spontaneous and mostly invisible to others. This presents challenges and opportunities for the field of LA.

\section{A VISION FOR PROFESSIONAL LEARNING ANALYTICS}

An underlying vision for LA in professional contexts is to make both formal and informal learning processes traceable and more explicit in order to connect each professional with the knowledge they need (Littlejohn et al., 2012; de Laat \& Schreurs, 2013). This vision is based on a system of mutual support through which each professional connects with and contributes to the collective knowledge by connecting with people and networks to find relevant knowledge and experiences; consuming or using this knowledge and, in the process, creating new knowledge that is contributed back to the collective (Milligan, Littlejohn, \& Margaryan, 2014). These actions create a common capital through re-usable knowledge via the selective accumulation of shared by-products of individual activities motivated, initially, by personal utility (Convertino, Grasso, DiMicco, De Michelis, \& Chi, 2010, p. 15). These actions would be supported by a set of algorithms, data mining mechanisms, and analytics that create a "common capital through re-usable knowledge via the selective accumulation of shared by-products of individual activities motivated, initially, by personal utility" (Convertino et al., 2010, p. 15).

Professional learning is influenced by the learner's internal motivation and personal agency in connecting to and interacting with the collective knowledge and their environment (Littlejohn \& Hood, 2016), therefore there are two critical components to this vision. First, to ensure personal agency it is critical that professionals have the ability to self-regulate their learning. Second, to trigger motivation, learning (and learning systems) should be integrated with, rather than separate from, work practices. In moving towards this vision, a range of approaches to Professional LA have been developed over the past few years.

\section{Analytics in Action}

LA is a multidisciplinary area using ideas from learning science, computer science, information science, educational data mining, knowledge management highlighting, and, more recently, artificial intelligence (Gillani \& Enyon, 2014). Emerging areas of analytics make use of complex datasets containing multiple data types such as discourse data, learner disposition data, and biometrics (Siemens \& Long, 2011). Techniques used in LA include discourse analysis, where learners discussions and actions provide opportunity for helpful interventions (Gillani \& Enyon, 2014); semantic analysis, tracing the relationship between learners and learning (Wen, Yang, \& Rosé, 2014), learner disposition analytics, identifying affective characteristics associated with learning (Buckingham Shum \& Deakin Crick, 2012) and content analytics, including recommender systems that filter and deliver content based on tags and ratings supplied by learners. These techniques are useful for encapsulating the complex factors that influence how professionals learn.

Diverse approaches to LA have been field-tested in various professional settings. Some methods capitalize on the data generated as a by-product of learning in digital systems. Others use new approaches, for example social learning analytics (SLA) that examine how individuals and groups learn and develop new knowledge. These methods and systems capitalize on new forms of organization, different feedback formats, and the numerous ways people and the resources they require for their learning and work can be brought together. Many are in the early stages of development and this section examines different approaches and their impact on learning and performance.

\section{Accelerating Just-in-Time Learning}

Some approaches to PLA are aimed towards embedding agile approaches to professional learning in work settings. Many organizations recognize that training is not effective if professionals learn a new process then do not use their new knowledge and embed it within their practice. Recognizing the importance of enabling people to learn new expertise at the point of need, organizations have been seeking ways to capture and disseminate expertise.

Wearable Experience for Knowledge Intensive Training (WEKIT) ${ }^{1}$ is exploring if and how data generated through smart Wearable Technology can capture expertise and disseminate the know-how to inexperienced professionals at the point of need. WEKIT is based on a three-stage process: mapping skill development pathways, capturing and codifying expertise, and making the expertise available to novices at the point of need. In the first stage, a community of professionals and stakeholders ${ }^{2}$ map out a recognized skill development pathways for industry. In the second stage, a group of software developers use the pathway templates to develop technology tools to support novices in learning new procedural knowledge - for example how to turn on (or off) a specialist valve. Finally, the expertise is transmitted to the novice via an augmented visual interface. Tools such as head-mounted digital displays allow the novice to see the valve overlaid with instructions on how to switch it on safely. Through

\footnotetext{
${ }^{1}$ https://wekit-community.org/ ${ }^{2}$ the WEKIT.club
} 
wearable and visual devices, the system directs each professional's attention to where it is most needed, based on an analysis of user needs. The system aims to make informal learning processes traceable and recognizable so that novices can rapidly develop expertise. In this way, learning can be agile, as the need arises.

The WEKIT project commenced in December 2015 and evaluations of the effectiveness of the approach have yet to be published. However, the three key steps in the transfer of expertise in the WEKIT methodology all have risks associated with them. First, expertise development pathways are difficult to model. Experts are involved in building the pathways and algorithms to support expertise development in an attempt to capture and codify the expertise accurately. However, it is difficult for an expert to understand the optimal learning pathway that will enable each novice's expertise development, since this depends on the novice's prior experience. Second, not all expertise can be codified. Augmented visual interfaces and collaborative digital interfaces can help with expertise development, but tacit expertise, such as the "gut feeling" that a piece of equipment is operating optimally, takes time to be developed. Thirdly, the novice has to be actively involved in learning new expertise, rather than simply following instructions. This is particularly relevant in work settings where task outcomes are difficult to predict, such as knowledge work. Learning in these situations is most effective when integrated with work tasks. Therefore, an emerging trend is to embed PLA within work-integrated systems: platforms that support experts and novices in co-working, smart systems or augmented reality environments, such as those described earlier.

\section{Exploiting Organizational Networks}

By tapping into informal professional networks, people can achieve the kind of agile learning described by Clow (2013). This type of self-governing, bottom-up approach to professional development requires a deep understanding of how and where professionals interact and exchange ideas about their work. Making informal learning practices and networks visible is a key aim for PLA. de Laat \& Schreurs (2013) demonstrated that LA techniques can visualize informal professional networks. Using a tool based on social network analysis - the network awareness tool (NAT) - they detected multiple isolated networks of teachers within a single organization. More recent work uses wearable devices to track professional networks in health care settings (Endedijk, 2016). By exploiting these informal professional networks, organizations have a mechanism to improve human social capital and learning. However, the study illustrates the limited extent of connections across professional networks, so multiple methods of exploiting networks are needed.

Learning Layers ${ }^{3}$ exploits networks and relationships at the individual, organizational, and inter-organizational levels to improve performance. Professionals working within and across regional small to medium enterprises (SMEs) in different European countries work together in web-based, networked environments to build ideas and knowledge. The system exploits semantic technologies to analyze and support the co-production of knowledge by connecting people and making recommendations (Ley et al., 2014).

Technology environments tested in the health and construction sectors illustrate ways professionals work and learn together at three levels. As people work together, they learn how to develop different types of knowledge including technical knowledge (knowwhat), procedural or practical knowledge (know-how), and scientific or theoretical knowledge (know-why) to help them make informed choices as to how they will carry out new work tasks (Attwell et al., 2013). At the organizational level, as people collaborate across different SMEs, the individual organizations share knowledge and learn. Thirdly, the companies are grouped in national clusters, so learning occurs across organizations (Dennerlein et al., 2015). LA tools are being co-developed with the professionals themselves and with key stakeholders. An open design library ${ }^{4}$ is used to store and disseminate ideas for professional learning while an open developer library ${ }^{5}$ hosts prototype tools and codes for developers to work on. The principle that professionals themselves have the best knowledge about learning for highly specialized roles is central to several LA systems and tools.

\section{Making use of Specialist Expertise}

Responsive Open Learning Environments (ROLE) ${ }^{6}$ are being developed to enable professionals to adapt to and deal with change and uncertainty in their work and learning (Kirschenmann, Scheffel, Friedrich, Niemann, \& Wolpers, 2010). Rather than using an all-encompassing, enterprise system, the learning environment can be personalized by each individual learner. Each professional can browse and select a set of web-based software tools with specific functions that support learning for a specific role. The tools can be combined to form new components and functionalities. By establishing a unique combination of tools and resources, the professional embeds her own expertise within the environment. This combination of tools and resources can be reproduced and adapted to support other professionals with similar work and learning needs.

\footnotetext{
${ }^{3}$ learning-layers.eu

${ }^{4}$ odl.learning-layers.eu

${ }^{5}$ developer.learning-layers.eu

${ }^{6}$ role-project.eu
} 
The basic principle that underpins ROLE is well defined; in highly specialized roles, professionals themselves are best placed to decide on their learning needs (Kroop, Mikroyannidis, \& Wolpers, 2015). However, from a professional learning perspective, there are two main overarching difficulties. First, professionals may not have the skills to implement their decisions. ROLE is based on an open framework that allows the development of technology tools or widgets that support specific aspects of professional learning. These widgets are developed through open competitions, where developers are encouraged to create new tools and functionalities. Ideally, developers who have a deep understanding of the job role would create the widgets: if the professionals themselves can write the algorithms for the widgets, then their expertise is embedded within the code. However, not all professionals can write code, so, for many professions the widgets tend to be developed by people who don't have a deep understanding of the job role. The second difficulty is that professionals have to be able to identify and act upon their learning needs. The ROLE environment includes a course on becoming a self-regulated learner. ${ }^{7}$ However, a problem is that while some aspects of self-regulation can be learned, such as developing strategies to set learning goals, other facets of self-regulation, such as self-confidence, are developed through lifelong experiences.

\section{Encouraging Active Learning}

Two other examples of LA systems based on self-regulated learning theory are LearnB and Mirror. LearnB has been piloted in the automotive industry (Siadaty, Gašević \& Hatala, 2016). What this tool has in common with the previous systems is that it encourages professionals to self-regulate their learning. The tool is designed around a self-regulated learning framework, SRL@Work, which is used to gather data on factors that influence self-regulation. These factors include how learning goals are planned and the specific range of activities that people engage in as they share and build knowledge for work. Learn B uses Social Semantic Web technologies to gather and analyze these data in order to identify and connect people with similar learning and development goals (Siadaty et al., 2012). Common goals are identified and analyzed using the semantic capabilities of the system. Then the system uses social technologies to recommend topics people might benefit from learning, based on the learning patterns of others.

The LearnB system serves as a "developmental radar" allowing professionals to source and assess potentially useful connections with other people and with rele-

\footnotetext{
ROLE Course in Becoming a Self-regulated Learner (http://www. open.edu/openlearnworks/course/view.php?id=1490
}

vant knowledge (Siadaty, Jovanović, Gašević, Jeremić, \& Holocher-Ertl, 2010; Holocher-Ertl et al., 2012). It can be used to advise professionals on their learning strategies while monitoring their learning progress. The idea here is that people might learn effectively by using strategies that have been effective for other people with analogous experience. The system supports professionals not only in documenting their learning experiences, but also in making these experiences available for others who might benefit from learning in a similar way in the future. By documenting learning experiences, it is possible to share and compare with the performance of others or against organizational benchmarks. It might be useful, for example, to know that it takes an average of six months' experience to become competent in a new procedure. On the other hand, it may be reassuring to know that a new skill can be learned in a few hours (Siadaty et al., 2012).

The Learn B trial demonstrated the importance of integrating the system with active development of professionals' self-regulated learning skills. Professionals who used Learn B benefitted from having their attention directed towards useful knowledge, sometimes sourced from contexts or departments different from those in which they worked. They also perceived the usefulness of having access to data on other peoples' informal work and learning practices that helped them to understand the ways other people learned. They perceived that they benefitted from updates about their social context - knowing, for example, the actions other people were taking to learn - and by being informed about how the available learning resources were used by their colleagues (Siadaty, 2013). However, a critical point is that these professionals were operating within a traditional organizational culture with the sort of "top down" competence systems discussed by Clow (2013) where the organization predetermines the competencies needed for each job role and recommends the ways people demonstrate how they learn these capabilities.

Mirror $^{8}$ is an analytics-based system that supports professionals in learning from their own and others experiences. Reflection is a significant component of self-regulated learning that may improve learning and performance through motivational and affective factors (Littlejohn \& Hood, 2016). The Mirror system is based on a set of applications ("Mirror" apps) designed to facilitate informal learning during work (Kump, Knipfer, Pammer, Schmidt, \& Maier, 2011). These apps were used in case worker settings to support analysis of individual and team actions. These reflections allowed both individuals and teams to learn which practices had the most impact within their organization. Eval-

\footnotetext{
${ }^{8}$ www.mirror-project.eu
} 
uation studies found a clear link between individual and team learning and organizational learning (linked to Human Resource procedures, rewards, and promotions) (Knipfer, Kump, Wessel, \& Cress, 2013). Without a parallel shift in the culture and the mindsets of people within the organization, new analytics systems will have limited impact.

\section{CONCLUSION: FUTURE PROFESSION- AL LEARNING ANALYTICS}

Novel approaches to LA are already supporting professionals in improving their performance. Analysis of these approaches point to emerging themes that can inform future work.

Several approaches to analytics use machine-based analytics to augment human intelligence. However, the connection between the system and the human is a point of risk for a number of reasons. First, professionals must be able to identify and act upon their learning needs, so the ability to self-regulate learning is critical to the success of many analytics techniques. Second, without a parallel shift in the culture and the mindsets of people within the organization, learning systems based on analytics will have limited impact. Implementation of approaches to LA should consider these human elements.

Some LA techniques use network analysis to gather data. Workplace learning is most effective when learning processes are aligned with organizational and project goals (Kimmerle, Cress \& Held, 2010; Kozlowski \& Klein, 2000). Network analysis should aim to align individual learning activities intelligently with organizational learning goals.

Other promising approaches to PLA are based on the development of software applications (or apps). Ideally, professionals who have the specific expertise would write the code. However, not all professionals have the ability write code, so, for many professions apps tend to be developed by people who do not have a deep understanding of the job role. This problem is likely to be more significant in non-technical sectors.

Many PLA methods aim to embed agile approaches to learning through capturing and disseminating expertise. There are a number of problems associated with this approach; for example, not all expertise can be codified - expertise development pathways are difficult to model since each individual has a unique baseline of prior knowledge and professionals to be actively involved in learning new expertise. These difficulties illustrate that the analytics solutions have to not only address the technical and practical aspects of expertise development, but deal with affective and motivational issues as well.

Although in its infancy, professional learning analytics is set to form a foundation for future learning and work. However, careful attention has to be paid to the alignment of the knowledge on how professionals learn with analytics applications.

\section{REFERENCES}

Attwell, G., Heinemann, L., Deitmer, L., Kämaäinen, P. (2013). Developing PLEs to support work practice based learning. In eLearning Papers \#35, Nov. 2013. http://OpenEducationEuropa.eu/en/elearning_papers

Argyris, C., \& Schon, D. A. (1974). Theory in practice: Increasing professional effectiveness. San Francisco, CA: Jossey-Bass, 1974.

Baker, R. S. (2016). Stupid tutoring systems, intelligent humans. International Journal of Artificial Intelligence in Education, 26(2), 600-614.

Berendt, B., Vuorikari, R., Littlejohn, A., \& Margaryan, A. (2014). Learning analytics and their application in technology-enhanced professional learning. In A. Littlejohn \& A. Margaryan (Eds.), Technology-enhanced professional learning: Processes, practices and tools (pp. 144-157). London: Routledge.

Boud, D., \& Garrick, J. (1999). Understanding learning at work. Taylor \& Francis US.

Billett, S. (2004). Workplace participatory practices: Conceptualising workplaces as learning environments. Journal of Workplace Learning, 16(6), 312-324.

Buckingham Shum, S., \& Deakin Crick, R. (2012). Learning dispositions and transferable competencies: Pedagogy, modelling and learning analytics. Proceedings of the $2^{\text {nd }}$ International Conference on Learning Analytics and Knowledge (LAK '12), 29 April-2 May 2012, Vancouver, BC, Canada (pp. 92-101). New York: ACM. 
Buckingham Shum, S., \& Ferguson, R. (2012). Social learning analytics. Educational Technology \& Society, 15(3), $3-26$.

Clow, J. (2013) Work practices to support continuous organisational learning. In A. Littlejohn \& A. Margaryan (Eds.), Technology-enhanced professional learning: Processes, practices, and tools (pp. 17-27). London: Routledge.

Collin, K. (2008). Development engineers' work and learning as shared practice. International Journal of Lifelong Education, 27(4), 379-397.

Convertino, G., Grasso, A., DiMicco, J., De Michelis, G., \& Chi, E. H. (2010). Collective intelligence in organizations: Towards a research agenda. Proceedings of the 2010 ACM Conference on Computer Supported Cooperative Work (CSCW 2010), 6-10 February 2010, Atlanta, GA, USA (pp. 613-614). New York: ACM. http:// research.microsoft.com/en-us/um/redmond/groups/connect/CSCW_10/docs/p613.pdf

Dennerlein, S., Theiler, D., Marton, P., Santos, P., Cook, J., Lindstaedt, S., \& Lex, E. (2015) KnowBrain: An online social knowledge repository for informal workplace learning. Proceedings of the $10^{\text {th }}$ European Conference on Technology Enhanced Learning (EC-TEL '15), 15-17 September 2015, Toledo, Spain. http://eprints.uwe. ac.uk/26226

Endedijk, M. (2016) Presentation at the Technology-enhanced Professional Learning (TePL) Special Interest Group, Glasgow Caledonian University, May 2016.

Eraut, M. (2000). Non-formal learning and tacit knowledge in professional work. British Journal of Educational Psychology, 70(1), 113-136.

Eraut, M. (2004). Informal learning in the workplace. Studies in Continuing Education, 26(2), 247-273.

Eraut, M. (2007). Learning from other people in the workplace. Oxford Review of Education, 33(4), 403-422.

Engeström, Y. (1999). Innovative learning in work teams: Analyzing cycles of knowledge creation in practice. Perspectives on activity theory, 377-404.

Engeström, Y. (2008). From teams to knots: Activity-theoretical studies of collaboration and learning at work. Cambridge, UK: Cambridge University Press.

Ferguson, R. (2012) Learning analytics: Drivers, developments and challenges. International Journal of Technology Enhanced Learning, 4(5-6), 304-317.

Fuller, A., Ashton, D., Felstead, A., Unwin, L., Walters, S., \& Quinn, M. (2003). The impact of informal learning for work on business productivity. London: Department of Trade and Industry.

Fuller, A., \& Unwin, L. (2004). Integrating organizational and personal development. Workplace learning in context, 126.

Gillani, N., \& Eynon, R. (2014). Communication patterns in massively open online courses. The Internet and Higher Education, 23, 18-26.

Harteis, C., \& Billett, S. (2008). The workplace as learning environment: Introduction. International Journal of Educational Research, 47(4), 209-212.

HEC Report (2016) From bricks to clicks: Higher Education Commission Report http://www.policyconnect. org.uk/hec/sites/site_hec/files/report/419/fieldreportdownload/frombrickstoclicks-hecreportforweb. pdf

Holocher-Ertl, T., Fabian, C. M., Siadaty, M., Jovanović, J., Pata, K., \& Gašević, D. (2011). Self-regulated learners and collaboration: How innovative tools can address the motivation to learn at the workplace? Proceedings of the $6^{\text {th }}$ European Conference on Technology Enhanced Learning: Towards Ubiquitous Learning (EC-TEL 2011), 20-23 September 2011, Palermo, Italy (pp. 506-511). Springer Berlin Heidelberg.

IBM (2008) Making change work. IBM Global Study. http://www-07.ibm.com/au/pdf/making_change_work. pdf

de Laat, M., \& Schreurs, B. (2013). Visualizing informal professional development networks: Building a case for learning analytics in the workplace. American Behavioral Scientist, 57(10), 1421-1438. 
Kimmerle, J., Cress, U., \& Held, C. (2010). The interplay between individual and collective knowledge: Technologies for organisational learning and knowledge building. Knowledge Management Research \& Practice, 8(1), 33-44.

Kirschenmann, U., Scheffel, M., Friedrich, M., Niemann, K., \& Wolpers, M. (2010). Demands of modern PLEs and the ROLE approach. In M. Wolpers, P. A. Kirschner, M. Scheffel, S. N. Lindstaedt, \& V. Dimitrova (Eds.), Proceedings of the $5^{\text {th }}$ European Conference on Technology Enhanced Learning, Sustaining TEL: From Innovation to Learning and Practice (EC-TEL 2010), 28 September-1 October 2010, Barcelona, Spain (pp. 167-182). Springer Berlin Heidelberg.

Kozlowski, S. W. J., \& Klein, K. J. (2000). A multilevel approach to theory and research in organizations: Contextual, temporal, and emergent processes. In K. J. Klein \& S. W. J. Kozlowski (Eds.), Multilevel theory, research and methods in organizations: Foundations, extensions, and new directions (pp. 3-90). San Francisco, CA: Jossey-Bass.

Knipfer, K., Kump, B., Wessel, D., \& Cress, U. (2013). Reflection as a catalyst for organisational learning. Studies in Continuing Education, 35(1), 30-48.

Kroop, S., Mikroyannidis, A., \& Wolpers, M. (Eds.). (2015). Responsive open learning environments: Outcomes of research from the ROLE project. Springer.

Kump, B., Knipfer, K., Pammer, V., Schmidt, A., \& Maier, R. (2011) The role of reflection in maturing organizational know-how. Proceedings of the $1^{\text {st }}$ European Workshop on Awareness and Reflection in Learning Networks (@ EC-TEL 2011), 21 September 2011, Palermo, Italy.

Ley, T., Cook, J., Dennerlein, S., Kravcik, M., Kunzmann, C., Pata, K., \& Trattner, C. (2014). Scaling informal learning at the workplace: A model and four designs from a large-scale design-based research effort. British Journal of Educational Technology, 45(6), 1036-1048.

Littlejohn, A., \& Hood, N. (2016, March 18). How educators build knowledge and expand their practice: The case of open education resources. British Journal of Educational Technology. doi:10.1111/bjet.12438

Littlejohn, A., \& Margaryan, A. (2013). Technology-enhanced professional learning: Mapping out a new domain. In A. Littlejohn \& A. Margaryan (Eds.), Technology-enhanced professional learning: Processes, practices, and tools (Chapter 1). Taylor \& Francis.

Littlejohn, A., Milligan, C., \& Margaryan, A. (2012). Charting collective knowledge: Supporting self-regulated learning in the workplace. Journal of Workplace Learning, 24(3), 226-238.

Milligan, C., Littlejohn, A., \& Margaryan, A. (2014). Workplace learning in informal networks. Reusing Open Resources: Learning in Open Networks for Work, Life and Education, 93.

Nistor, N., Derntl, M., \& Klamma, R. (2015). Learning analytics: Trends and issues of the empirical research of the years 2011-2014. Proceedings of the $10^{\text {th }}$ European Conference on Technology Enhanced Learning: Design for Teaching and Learning in a Networked World (EC-TEL 2015), 15-17 September 2015, Toledo, Spain (pp. pp. 453-459). Springer.

Rienties, B., Boroowa, A., Cross, S., Kubiak, C., Mayles, K., \& Murphy, S. (2016). Analytics4Action evaluation framework: A review of evidence-based learning analytics interventions at the Open University UK. Journal of Interactive Media in Education, 2016(1). www-jime.open.ac.uk/articles/10.5334/jime.394/galley/596/ download/

Siadaty, M. (2013). Semantic web-enabled interventions to support workplace learning. Doctoral dissertation, Simon Fraser University, Burnaby, BC. http://summit.sfu.ca/item/12795

Siadaty, M., Gašević, D., \& Hatala, M. (2016). Associations between technological scaffolding and micro-level processes of self-regulated learning: A workplace study. Computers in Human Behavior, 55, 1007-1019.

Siadaty, M., Gašević, D., Jovanović, J., Pata, K., Milikić, N., Holocher-Ertl, T., ... \& Hatala, M. (2012). Self-regulated workplace learning: A pedagogical framework and semantic web-based environment. Educational Technology \& Society, 15(4), 75-88. 
Siadaty, M., Jovanović, J., Gašević, D., Jeremić, Z., \& Holocher-Ertl, T. (2010). Leveraging semantic technologies for harmonization of individual and organizational learning. In M. Wolpers, P. A. Kirschner, M. Scheffel, S. N. Lindstaedt, \& V. Dimitrova (Eds.), Proceedings of the $5^{\text {th }}$ European Conference on Technology Enhanced Learning, Sustaining TEL: From Innovation to Learning and Practice (EC-TEL 2010), 28 September-1 October 2010, Barcelona, Spain (pp. 340-356). Springer Berlin Heidelberg.

Siemens, G., \& Long, P. (2011) Penetrating the fog: Analytics in learning and education. EDUCAUSE Review, 46(5), 31-40. http://net.educause.edu/ir/library/pdf/ERM1151.pdf

Tynjälä, P. (2008). Perspectives into learning at the workplace. Educational Research Review, 3(2), $130-154$.

Tynjälä, P., \& Gijbels, D. (2012). Changing world: Changing pedagogy. In P. Tynjälä, M.-L. Stenström, \& M. Saarnivaara (Eds.), Transitions and transformations in learning and education (pp. 205-222). Springer Netherlands.

Wen, M., Yang, D., \& Rosé, C. (2014). Sentiment analysis in MOOC discussion forums: What does it tell us? In J. Stamper et al. (Eds.), Proceedings of the $7^{\text {th }}$ International Conference on Educational Data Mining (EDM2014), 4-7 July 2014, London, UK. International Educational Data Mining Society. http://www.cs.cmu.edu/ mwen/papers/edm2014-camera-ready.pdf

Wolff, A., Zdrahal, Z., Nikolov, A., \& Pantucek, M. (2013, April). Improving retention: Predicting at-risk students by analysing clicking behaviour in a virtual learning environment. Proceedings of the $3^{\text {rd }}$ International Conference on Learning Analytics and Knowledge (LAK '13), 8-12 April 2013, Leuven, Belgium (pp. 145-149). New York: ACM. 